\title{
Effect of friction stir processing on human health
}

\section{Nidhi Sharma*}

Department of Mechanical Engineering,

GNIT,

Greater Noida, India

Email: nid.sharma83@gmail.com

*Corresponding author

\section{Mohd Atif Wahid}

Department of Mechanical and Automation Engineering,

DTC,

Greater Noida, India

Email: wahidatif89@gmail.com

\section{Pankul Goel}

Department of Mechanical Engineering,

IMS,

Ghaziabad, UP, India

Email: pankul.goel@gmail.com

\section{Kul Vaibhav Sharma}

Department of Civil Engineering,

MNIT,

Jaipur, India

Email: 2015rce9519@mnit.ac.in

\begin{abstract}
Friction stir processing is used to improve the surface structure and different properties of the metallic elements. FSP is performed in solid state particles of nano to $10 \mu \mathrm{m}$ in inserted inside the metallic element using a rotating and traversing FSP tool. FSP is considered as a green technology, but the use of very small size particles may have some adverse effect on the environment and in turn on human beings if inhaled during FSP. During FSP, the use of FSP powdered particles may contaminate the surrounding atmosphere. These tiny particles of very small size may adversely affect the human health if gets inhaled. Unfortunately, this aspect of FSP has not been studied and it also figures out the health friendliness of the FSP may be overrated. This paper focuses on the various factors of FSP related to its effect on the environment as well as on human health.
\end{abstract}

Keywords: friction stir processing; FSP; respiratory tract; powdered material; human health. 
Reference to this paper should be made as follows: Sharma, N., Wahid, M.A., Goel, P. and Sharma, K.V. (2020) 'Effect of friction stir processing on human health', Int. J. Forensic Engineering and Management, Vol. 1, No. 1, pp.53-61.

Biographical notes: Nidhi Sharma is an Associate Professor in the Department of Mechanical Engineering at Greater Noida Institute of Technology (GGSIPU), Greater Noida, India. She received her PhD in 2018 from Jamia Millia Islamia, New Delhi, India. Her major research interest includes welding, optimisation of design and manufacturing processes parameters, etc. She has nine years of teaching and five years of research experience. She has published more than 25 articles in reputed journals.

Mohd Atif Wahid is an Assistant Professor in the Department of Mechanical Engineering at Delhi Technological Campus (GGSIPU), Greater Noida, India. He received his $\mathrm{PhD}$ in 2018 from Jamia Millia Islamia, New Delhi, India. His major research interest includes welding, optimisation of design and manufacturing processes parameters, etc. He has published more than 25 articles in reputed journals.

Pankul Goel is an Associate Professor in the Department of Mechanical Engineering at IMS Engineering College, Ghaziabad. He received his $\mathrm{PhD}$ in 2018 from Jamia Millia Islamia, New Delhi, India. His major research interest includes welding, optimisation of design and manufacturing processes parameters, etc. He has published more than ten articles in reputed journals. He is also co-authored one book related to Engineering Mechanics and one monograph as well.

Kul Vaibhav Sharma is a research scholar in the Department of Civil Engineering at MNIT, Jaipur. He is pursuing his $\mathrm{PhD}$ in the area of Remote Sensing of Thermal Images. His major research interest includes urban heat island effect, thermal comfort and downscaling techniques and digital image enhancements, etc. He has published some conference papers and a book chapter.

This paper is a revised and expanded version of a paper entitled 'Inhaled particles deposition in human respiratory tract during friction stir processing' presented at Humanizing Work and Work Environment 2017 [HWWE], Department of Mechanical Engineering, AMU, Aligarh, 8th to 10th December, 2017.

\section{Introduction}

Aluminium and its alloys are used in various industrial applications and these are easy to fabricate in the required shape and size (Rigelsford, 2003). These alloys are further modified or processed to improve their properties through various processing techniques (Sharifitabar et al., 2011). Friction stir processing (FSP) is a one of the recently developed green technology, which is significantly used to improve the surface properties of various aluminium alloys (Welding, 2007). FSP is able to provide the localised modification in the microstructures of the surface and subsurface layers of the processed materials (Ma, 2008). FSP has been found effective to produce the high strain rate superplastic microstructure in aluminium alloys (Charit and Mishra, 2003). During FSP, a 
rotational and traversing tool plastically deforms the base metal by frictional heat and also due to forging and extrusion action and creates a stirring action inside the base material (Yazdipour and Dehghani, 2009). FSP parameters significantly affect the properties of the processed material (Sharma et al., 2018a). Tool pin profile affects the material mixing capabilities in the solid state and therefore affects the development of microstructure after the FSP (Sharma et al., 2018b). For the development of the homogeneous and defect free microstructure, the selection of optimum processing strategy is required (Sharma and Siddiquee, 2017). FSP creates different microstructure at both sides of the processed material due to the difference in the generated temperature at advancing and retreating side (Albakri et al., 2013). FSP can also be used as the welding and casting repairing technique (Besharati-Givi and Asadi, 2014). During FSP, the powdered particles are spread over the metallic surface. Further, the action of the rotating and traversing tool mixes this powdered material into the base metal matrix and improves the surface properties. The basic steps of the FSP are given below.

First, the grooves, holes are filled by powdered material manually or by using high-velocity oxygen fuel (HVOF) technique and atmospheric plasma spraying (APS) technique.

Further, an FSP pass is performed to seal the pre-placed powder inside the base material substrate using a pin-less shoulder tool.

Finally, a specifically designed FSP tool with a pin and shoulder is allowed to traverse over the surface of the base metal which stirrers/mixes the powdered material with the base material and enhances the material's properties.

During the second stage of FSP, some portions of pre-placed powdered materials remain unfilled and sealed in the substrate of the material and there is high possibility of the contamination of environmental air through this unutilised powdered material. Most commonly used powdered material during FSP for improving the surface properties of aluminium and its alloys are aluminium oxide, silicon carbide and titanium carbide (TiC) (Gangil et al., 2017). These all particles can adversely affect the human health if inhaled by the operator of the FSP. A study performed on friction stir welding (FSW) of aluminium alloy also suggests the emission of nano-scale and submicrometre particles of the base material (Pfefferkorn et al., 2010). FSW does not require any additionally powdered material, unlike the FSP, however, emission is observed. Tool wear is found as a reason for the emission during FSW (Gomes et al., 2014). Therefore, the emission of particles during FSP should be much higher due to the need of very fine powdered material along with an FSP tool for improving the surface properties and thus generates a need to study the adverse effect of FSP on human health. This paper is written to understand the effect of different particles on human health those are used in FSP which is claimed to be a green process.

\section{Respiratory/pulmonary system}

The respiratory/pulmonary system is used for exchange of gas/air in animals and plants. Human respiratory system can be majorly divided into three segments:

1 upper respiratory tract (extrathoracic/nasopharynx)

2 lower respiratory tract (tracheobronchial) 
3 alveolar/ pulmonary (Darquenne, 2006).

Nose, nasopharynx, mouth, oropharynx and laryngopharynx are the anatomic structures of the upper segment, trachea, bronchi, bronchioles (to terminal bronchioles) lies in the middle segment, and bronchioles, alveolar sacs, alveolar ducts, alveoli lie in the last segment (Lippmann et al., 1980) as shown diagrammatically in Figure 1.

Figure 1 Deposition mechanism of airborne particles in the different parts of human respiratory system

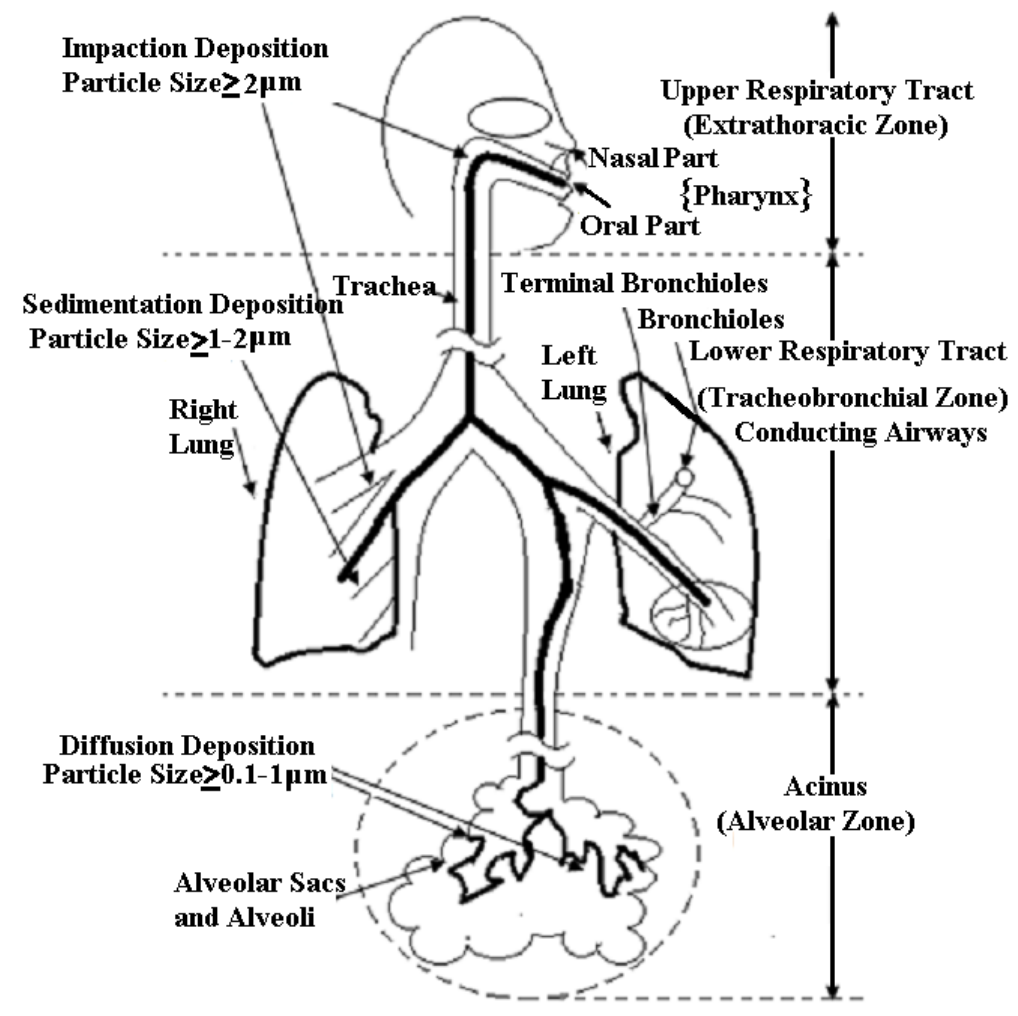

The breathing starts from the nose and mouth to the head and thorax and further till alveoli through the airways. The respiratory air gets exchanged in the alveoli and in the surrounding flowing blood. The respiratory system basically performs two functions: supplies oxygen $\left(\mathrm{O}_{2}\right)$ to the gas exchange region and removes the $\mathrm{CO}_{2}$ of equal volume to $\mathrm{O}_{2}$ which enters through alveolar capillaries. Apart from these, some other important functions which a respiratory system performs are:

1 temperature management of the lung airways

2 develops sterility towards infections and their adverse effects

3 removes unwanted inhaled particles, epithelial cells and senescent phagocytes, surface fluids and debris (Stellman, 1998).

All mentioned tasks are needed to be performed in a particular time period regularly throughout the life of a human being. However, this system can get malfunctioned, 
disturbed or abused by polluted air due to high concentrations of dust, smoke and pathogens which deteriorate the defence mechanisms.

\section{Deposition mechanisms of airborne particles in human}

Airborne particle density is quite higher near the FSP environment due to the presence of very small size metallic powder. Inhalation in such environment transports these particles to the lung which is the primary target for these particles. The inhaled airborne particles cause major health problems to a human being majorly to human lungs due to inhalation of impure air. These inhaled particles get a place in the airway and alveolar walls. The pattern of the particle deposition depends upon the clearance and redistribution of the inhaled or deposited particles which is the factor towards the development of pulmonary diseases. Nowadays, the risen pollution level has increased the accumulation of airborne particles in the human being. The most polluted areas where the density of airborne particles is quite higher are manufacturing industries, roads, offices, etc. Therefore, the potential health hazard arises due to deposition/retention of inhaled airborne particles in the respiratory tract or lungs of the human being. The airborne particles are measured in aerodynamic diameter (described as unit density sphere's diameter) and their deposition/retention majorly depends upon their sizes. The basic three mechanisms of particle deposition in the respiratory tract are:

1 impaction

2 sedimentation

3 diffusion (Bezemer, 2009).

The larger aerodynamic diameter (about $2 \mu \mathrm{m}$ ) particles posses quite a higher momentum or velocity and strikes or deposited in the larger airways through impaction mechanism. However, the particles of somewhat smaller diameter $(1 \mu \mathrm{m})$ possess relatively lesser flow velocity and generally get deposited in smaller through the sedimentation mechanism. The very small diameter particles $(0.1$ to $1 \mu \mathrm{m})$ rarely get deposited in a single tidal breath. In each tidal cycle, approximately $15 \%$ portion of the inspired tidal air retains during its exchange with lung air (Darquenne, 2006). The available time of the residual air in the lung is quite high and the airflow time in the different portion of the lung is variable. Thus, this situation creates favourable for the volumetric exchange of particles in the lung or the particle may diffuse here.

\section{Health effect of FSP}

Very small nano size powdered particles are generally used in FSP (Gangil et al., 2017). These particles may get transferred through the respiration system to the alveolar zone where they may get diffused. The air contamination during the FSP process is summarised in Table 1.

During the first FSP stage when powdered material is filled in the grooves or placed over the workpiece surface, the surrounding air gets contaminated due to the direct exposure of FSP powder in the environment. There is a higher possibility of the 
inhalation of this contaminated air by the FSP operator. This process should be controlled by preventing the direct exposure of metallic powder with atmosphere by designing a special chamber which possesses the mechanism to fill the powdered material over the workpiece surface (groove) and also isolates the base metal and powdered material unit from the environment. The powder spreading step over the workpiece should be performed over the FSP unit after fixing it in fixture inside a closed enclosure so that the spread metal powder do not expose to open atmosphere to further contaminate the air.

Table 1 Atmospheric contamination during FSP

\begin{tabular}{lccl}
\hline FSP stages & $\begin{array}{c}\text { Handling techniques } \\
\text { for powder }\end{array}$ & $\begin{array}{c}\text { Comparative air } \\
\text { contamination }\end{array}$ & \multicolumn{1}{c}{ Reason } \\
\hline $\begin{array}{l}\text { Filling of powder } \\
\text { over the surface }\end{array}$ & Manual filling & Lower & $\begin{array}{l}\text { Powder is exposed to } \\
\text { atmosphere }\end{array}$ \\
$\begin{array}{l}\text { Packing of powder } \\
\text { inside the metallic } \\
\text { surface }\end{array}$ & $\begin{array}{c}\text { FSP using pinless } \\
\text { tool (only shoulder) }\end{array}$ & Maximum & $\begin{array}{l}\text { Dispersion and spreading of } \\
\text { metal powder in the } \\
\text { atmosphere by tool } \\
\text { movement }\end{array}$ \\
$\begin{array}{l}\text { Removing of excess } \\
\text { unutilised powder } \\
\text { after packing }\end{array}$ & Manual removing & Higher & $\begin{array}{l}\text { Incompletely filled powder } \\
\text { is difficult to collect } \\
\text { completely and some } \\
\text { portion gets mixed in the } \\
\text { environment }\end{array}$ \\
$\begin{array}{l}\text { Powder dispersion } \\
\text { and mixing }\end{array}$ & $\begin{array}{l}\text { FSP using the } \\
\text { appropriate FSP tool } \\
\text { with pin }\end{array}$ & Minimum & $\begin{array}{l}\text { Due to varisation of low } \\
\text { melting point elements }\end{array}$ \\
\hline
\end{tabular}

The removal of excess metal powder should be also controlled and inside a closed enclosure to prevent the air contamination. The spread metal powder is packed inside the base metal substrate by an FSP pass using a pinless shouldered tool. During this stage, all the previously placed powdered material does not get filled inside the base metal substrate and the unfilled powder also gets momentum by the FSW tool movement. The momentum created in the powder particles increases the intensity of the atmospheric contamination which is highest at this stage.

During the last stage of FSP, the covered powdered material is mixed with the base metal by plastic deformation and stirring mechanism created by the movement of FSP rotating and traversing tool having appropriate tool pin. The air contamination is lesser in this stage if all the materials get mixed with the base metal, however, the surface defect may create some amount of air contamination.

The selection of the best suitable FSW process parameters, i.e., rotational speed, welding speed, shoulder/pin diameter and their shape, tool material, tool tilt angle, etc. may effectively cover or mix the powdered material with base material (Sharma et al., 2017). The careful selection of FSW parameters controls the air contamination or the adverse effect on human health. 


\section{Effect of different FSP powdered materials on human}

\subsection{Aluminium oxide}

Inhalation of aluminium and its oxide for a longer period may negatively affect the upper lobes of lungs and may create the pulmonary fibrosis, Shaver's disease, a severe pneumoconiosis, pneumothorax (Kusaka et al., 2001). During FSP, aluminium and its alloys are majorly used base materials or powder material and therefore may adversely affect the FSP operator.

\subsection{Silicon carbide}

Silicosis is a dangerous fibrotic disease which happens due to continuous inhalation and retention of silica (Fotedar et al., 2010). The pulmonary reaction occurring in the lungs due to the presence of silica is the reason behind the silicosis. Moreover, the continuous exposure to the atmosphere containing the silicon oxide may create another serious disease by affecting the upper lobes of the lungs known as pneumothorax (Mishra et al., 2014).

\subsection{Titanium carbide}

The contaminated air with $\mathrm{TiC}$ may cause irritation of the reparatory tract is inhaled for a short time period. However, the prolonged or repeated inhalation of $\mathrm{TiC}$ contaminated air may severely affect the lungs and its functioning (Coates and Watson, 1971). Pneumoconiosis disease is mostly observed in the worker operating in the $\mathrm{TiC}$ contaminated environment (Sprince et al., 1984).

\section{Recommended work practices during FSP}

1 The inhalation of metallic powdered particles should be prevented by wearing a good quality mask. The mask should be able to prevent the transmission of nano size particles to the human body through respiration system.

2 FSP should be performed in a close atmosphere inside an enclosure. The direct exposure of metallic powders with atmosphere should be avoided. The fixture should be specially designed to accommodate the manual or mechanical filling of powdered material in an enclosure.

3 The removal of excess unutilised metal powder should be also in closed atmosphere and the fixture should be designed to consider this aspect also.

4 The still air atmosphere should be maintained around the FSP unit to control the particles mixing with the atmosphere. Also, the use of exhaust system for removal or contaminated air and insertion of fresh air at the workplace may control the air contamination. 


\section{Conclusions}

The available literature suggests that the FSP is a green technology, but the use of metallic powder raises a question of concern on this claim. FSP may negatively affect the human health due to the airborne metallic powdered particles used during FSP if inhaled by the operator. The size of used powdered particles is usually very small and these escape the inbuilt defence mechanism of the respiratory system to transfer in the human body and reaches of the lungs. The prevention of atmospheric contamination by such particles is the remedy to prevent the lung diseases. Information pertaining to the effect of different FSP process parameter on the atmospheric contamination by the spread and release of particles in the atmosphere is not much available. It is recommended to practice the safe and controlled work practices during FSP in order to prevent air contamination. FSP is a finest technique to improve the surface properties of the materials and the prevention of air contamination will add to its environmentally friendly attribute.

\section{References}

Albakri, A.N., Mansoor, B., Nassar, H. and Khraisheh, M.K. (2013) 'Thermo-mechanical and metallurgical aspects in friction stir processing of AZ31 Mg alloy - a numerical and experimental investigation', Journal of Materials Processing Technology, Vol. 213, No. 2, pp.279-290.

Besharati-Givi, M.K. and Asadi, P. (2014) Advances in Friction-stir Welding and Processing, Elsevier, Woodhead Publishing in Mechanical Engineering, Elsevier.

Bezemer, G.F.G. (2009) Particle Deposition and Clearance from the Respiratory Tract, Master's thesis.

Charit, I. and Mishra, R.S. (2003) 'High strain rate superplasticity in a commercial $2024 \mathrm{Al}$ alloy via friction stir processing', Materials Science and Engineering: A, Vol. 359, No. 1, pp.290-296.

Coates, E.O. and Watson, J.H. (1971) 'Diffuse interstitial lung disease in tungsten carbide workers', Annals of Internal Medicine, Vol. 75, No. 5, pp.709-716.

Darquenne, C. (2006) 'Particle deposition in the lung', Encyclopedia of Respiratory, Vol. 3, pp.300-304, Elsevier Ltd., Amsterdam, UK.

Fotedar, S., Chaudhary, D., Singhla, V. and Narang, R. (2010) 'Silicosis with bilateral spontaneous pneumothorax', Lung India: Official Organ of Indian Chest Society, Vol. 27, No. 3, p.173.

Gangil, N., Siddiquee, A.N. and Maheshwari, S. (2017) 'Aluminium based in-situ composite fabrication through friction stir processing: a review', Journal of Alloys and Compounds, Vol. 715, pp.91-104.

Gomes, J.F., Miranda, R.M., Santos, T.J. and Carvalho, P.A. (2014) 'Emission of nanoparticles during friction stir welding (FSW) of aluminium alloys', Journal of Toxicology and Environmental Health, Part A, Vol. 77, Nos. 14-16, pp.924-930.

Kusaka, Y., Sato, K., Suganuma, N. and Hosoda, Y. (2001) 'Metal-induced lung disease: lessons from Japan's experience', Journal of Occupational Health, Vol. 43, No. 1, pp.1-23.

Lippmann, M.D.B.R.E., Yeates, D.B. and Albert, R.E. (1980) 'Deposition, retention, and clearance of inhaled particles', Occupational and Environmental Medicine, Vol. 37, No. 4, pp.337-362.

Ma, Z.Y. (2008) 'Friction stir processing technology: a review', Metallurgical and Materials Transactions A, Vol. 39, No. 3, pp.642-658. 
Mishra, P., Jacob, S.E., Basu, D., Panigrahi, M.K. and Govindaraj, V. (2014) 'Bilateral spontaneous pneumothorax in chronic silicosis: a case report', Case Reports in Pathology, Vol. 2014, pp.1-3, DOI: http://dx.doi.org/10.1155/2014/561861.

Pfefferkorn, E.F., Bello, D., Haddad, G., Park, Y.J., Powell, M., Mccarthy, J., Bunker, K.L., Fehrenbacher, A, Jeon, Y., Virji, A.M., Gruetzmacher, G. and Hoover, D.M. (2010) 'Characterization of exposures to airborne nanoscale particles during friction stir welding of aluminum', Annals of Occupational Hygiene, Vol. 54, No. 5, pp.486-503.

Rigelsford, J. (2003) 'The welding of aluminium and its alloys', Assembly Automation, Vol. 23, No. 2, Woodhead Publishing.

Sharifitabar, M., Sarani, A., Khorshahian, S. and Afarani, M.S. (2011) 'Fabrication of $5052 \mathrm{Al} / \mathrm{Al}_{2} \mathrm{O}_{3}$ nanoceramic particle reinforced composite via friction stir processing route', Materials \& Design, Vol. 32, No. 8, pp.4164-4172.

Sharma, N. and Siddiquee, A.N. (2017) 'Friction stir welding of aluminum to copper an overview', Transactions of Nonferrous Metals Society of China, Vol. 27, No. 10, pp.2113-2136.

Sharma, N., Khan, Z.A., Siddiquee, A.N., Shihab, S.K. and Wahid, M.A. (2018a) 'Effect of process parameters on microstructure and electrical conductivity during FSW of Al-6101 and pure copper', Materials Research Express, Vol. 5, No. 4, pp.1-20.

Sharma, N., Siddiquee, A.N., Khan, Z.A. and Mohammed, M.T. (2018b) 'Material stirring during FSW of Al-Cu: effect of pin profile', Materials and Manufacturing Processes, Vol. 33, No. 7, pp.786-794.

Sharma, N., Siddiquee, A.N. and Khan, Z.A. (2017) 'Friction stir welding defects in aluminum to copper joining: an overview', Journal of Manufacturing Technology Research, Vol. 9, Nos. 1/2, pp.69-79.

Sprince, N.L., Chamberlin, R.I., Hales, C.A., Weber, A.L. and Kazemi, H. (1984) 'Respiratory disease in tungsten carbide production workers', Chest, Vol. 86, No. 4, pp.549-557.

Stellman, J.M. (Ed.) (1998) Encyclopaedia of Occupational Health and Safety, International Labour Organization.

Welding, F.S. (2007) Processing, in Mishra, R.S. and Mahoney, M.W. (Eds.), ASM Int., Materials Park, Ohio.

Yazdipour, A. and Dehghani, K. (2009) 'Modeling the microstructural evolution and effect of cooling rate on the nanograins formed during the friction stir processing of A15083', Materials Science and Engineering: A, Vol. 527, No. 1, pp.192-197. 